\title{
A Review of the Appropriateness of Existing Micro- and Meso-level Models of Athlete Development within Equestrian Sport
}

\author{
Donna de Haan \\ Faculty of Sport and Nutrition, Amsterdam University of Applied Science, the Netherlands \\ *Corresponding Author: d.de.haan@hva.nl
}

Copyright $\bigcirc 2017$ by authors, all rights reserved. Authors agree that this article remains permanently open access under the terms of the Creative Commons Attribution License 4.0 International License

\begin{abstract}
The aim of this paper was to use a case study approach to review the appropriateness of existing microand meso-level models of athlete development within the sport specific context of equestrianism. At a micro-level the Long Term Athlete Development (LTAD) model was chosen. At a meso-level, the Sport Policy factors that Lead to International Sporting Success (SPLISS) model was chosen with specific focus on Pillar 4 (talent identification and development systems). To assess the relevance or fit of these models, policy documentation from the British Equestrian Federation (BEF) which includes information on athlete profiling and performance pathways were reviewed. Results from this study indicate that talent identification and development of the rider at the point of specialization (micro-level) and performance/competition pathways (meso-level) have a degree of synergy. However, due to the potential longevity of riders' careers, and the required combination of an elite rider with an elite horse, it is difficult to map this at a senior level. The findings illustrate that due to these sport-specific variables, equestrianism does not 'fit' within these models and requires a unique 'dual athlete horse and rider' talent identification and development system.
\end{abstract}

Keywords LTAD, SPLISS, Equestrianism, Athlete Development Models

\section{Introduction}

Within the field of elite sport there is a consensus that factors that determine elite success can be examined at three levels; macro-, meso-, and micro-level, e.g. [1-5]. With regards to the macro-level, research shows that over $50 \%$ of the international success of countries is explained mainly by three variables; population, wealth (expressed as Gross Domestic Product by Capita) and (former) communism [6].
Sport policy makers are unable to influence these factors and therefore the focus of studies over the past 20 years with regard to the examination of elite sport have tended to concentrate on the meso-level e.g., [1-3] [7]. These meso-level studies have attempted to identify the critical factors required for successful elite athlete development. Micro-level factors are concerned with the characteristics of the individual athletes, such as their genetic qualities and the influence of their close environment. At a meso-level, sport policy makers create talent identification policies and performance pathways and at a micro-level sport scientist and coaches are concerned with understanding and developing athletic potential.

Arguably one of the most inclusive studies of meso-level factors that influence international sporting success, is the "Sport Policy Factors that Lead to International Sporting Success" (SPLISS) model [8]. SPLISS identifies 9 pillars (or policy areas) that influence international sporting success, Pillar 4 is specifically linked to Talent Identification and Development Systems. At a micro-level, the "Long Term Athlete Development" (LTAD) model has been proposed by a variety of national governing bodies to offer a first step to considering the approach to talent development. The LTAD model, which is primarily a physiological perspective, presents an advancement of understanding of developing athletic potential alongside biological growth [9]. De Bosscher et al., [10] explain that analyses across the microand meso-levels are important in order to provide a holistic view of athlete development and practical recommendations. In addition, [11] and [10] recommend that these analyses require the consideration of sport specific issues in order to provide deep evaluations and context for the use and place of these models.

The purpose of this paper is to address the call for holistic, sport specific analysis by using a case study approach to review the appropriateness of existing micro- and meso-level models of athlete development within the sport of equestrianism, specifically the Olympic disciplines of 
Dressage, Showjumping and Eventing. There are many aspects of equestrian sport which make it unique. For example, the relationship between athlete and animal [12]. The fact that equestrian sport is not subjected to the dominant binary sex segregation of most sports provides a unique opportunity to review how athlete development models are constructed in the context of a sex-integrated sport. For example, the equestrian team selected to represent Great Britain at the Rio Olympics, across the three disciplines consisted of 7 male riders and 8 female riders. Finally the age at which riders compete at the elite level is also of interest. For example the age of riders selected to represent Great Britain at the Rio Olympic Games, ranged from 20-60 years. Therefore, within this sport-specific context, there appear to be several unique variables which may influence athlete development and success.

The research question driving this investigation is: "how can two commonly used, existing micro- and meso-level models be applied to equestrian sport?" To assess the relevance or fit of these models, policy documentation from the British Equestrian Federation (BEF) which includes information on athlete profiling and performance pathways has been reviewed. The section that follows provides a brief overview of the LTAD model, followed by a section on the SPLISS model, with specific focus on Pillar 4. The place of equestrian sport within these models is then evaluated and discussed, before relevant conclusions and recommendations are drawn.

\section{LTAD Model}

As recognition of the political and commercial value of sport becomes more evident, so too does the perceived value of elite sport and the focus on developing elite athletes often supersedes government and policy initiatives targeted at mass sports participation [13]. Within this context, the development of progressive pathways that nurture talented athletes from junior to senior level has come to form a core focus for national governing bodies (NGBs) of sport. To the extent that, in England, for example, NGBs have been required to have a sport-specific LTAD plan in order to receive state funding [13]. Indeed, the LTAD model has come to represent a sport-wide set of principles that significantly influences sports policy in many countries including England. Created by sports scientist Istvan Balyi in the early 1990s, the goal of the LTAD model was to ensure that children learnt the fundamental skills required to be successful in sport, during their optimal physical development stages [13].

There are a several studies which have identified the numerous physical developmental processes that occur during childhood and adolescence and how they might influence short- and long-term athletic performance [14-17]. The LTAD model however, has been constructed on the basis that it combines successfully employed training methods alongside a greater scientific basis for children and adolescents [18, 19]. The LTAD model remains the prominent ideology used in the optimisation of long-term athletic performance preparation and development [9].

The LTAD model attempts to balance training load and competition throughout childhood and adolescence, as previously it has been suggested that there has been too much focus placed upon results rather than assisting optimal development processes $[20,21]$. There are seven stages within the basic LTAD model (Table 1). Stages 1, 2 and 3 are associated with developing physical literacy before puberty so children have the basic skills to be active for life. In this context physical literacy is purported to provide the foundation for those who choose to pursue elite training in one sport or activity after age 12 . Stages 4,5 and 6 provide elite training for those who want to specialise in one sport and compete at the highest level, maximizing the physical, mental and emotional development of each athlete. Finally, Stage 7 is about staying Active for Life through lifelong participation in competitive or recreational sport or physical activity. The notion that it takes at least 10 years or 10,000 hours of deliberate practice to excel, has become central to the LTAD model [22].

Table 1. Stages within the LTAD model

\begin{tabular}{|c|c|}
\hline Stage & Age \\
\hline Stage 1: Active Start & (0-6 years) \\
\hline Stage 2: Fundamentals & (girls 6-8, boys 6-9) \\
\hline Stage 3: Learn to Train & (girls 8-11, boys 9-12) \\
\hline Stage 4: Train to Train & (girls 11-15, boys 12-16) \\
\hline Stage 5: Train to Compete & (girls 15-21, boys 16-23) \\
\hline Stage 6: Train to Win & (girls 18+, boys 19+) \\
\hline Stage 7: Active for Life & (any age participant) \\
\hline
\end{tabular}

It is suggested that through objective physiological assessment tools (e.g. peak height velocity, peak weight velocity), coaches can account for individual maturation rates for each athlete so that they can apply the relevant training protocols depicted in each phase of the model. Such practice advances chronological age classification, which seems to be inherently flawed due to variation in growth and maturational rates between individuals and subsequent variance in training "readiness" [18], [21]. In addition, using appropriate training stimuli linked to natural growth and maturation processes (an additional factor from this model) utilizes the concept that there are "windows of opportunity" to accelerate and enhance physical development.

Whilst the LTAD model succeeds in offering practitioners a coaching framework using plausible principles, it is not without its critics. Numerous scholars have highlighted the potential for lack of implementation of the LTAD [23-26]. Indeed, while coaches from a range of sports in Martindale et al.'s [26] study suggested that de-emphasizing age-group success was crucial for effective 
implementation of talent identification pathways such as LTAD, they also recognized that this was not currently occurring. Similarly, others have suggested that the drive for early success pervades contemporary English sports culture $[24,25]$ and is often even built into athlete- and coach-selection procedures [25] despite evidence that an emphasis on winning contributes to dropout rates within competitive programmes [27,28].

Moreover, as a large proportion of coaching knowledge and practice comes from personal interpretations of previous experiences [23], [29-31], and an essential component of an effective training programme is the concept of individualisation [32]. This lack of monitoring of the implementation of LTAD has led to suggestions that policy slippage and incomplete implementation may occur [23]. Ford et al., [9] conclude that whilst the LTAD model has clearly advanced coaches' and practitioners' understanding of the importance of physiological principles and biological maturation alongside training young athletes, there are many unexplained / unsupported premises that undermine it and therefore they call for coaches' to be better educated in how to interpret and use the information within the model in a sport specific context.

\section{SPLISS Model}

SPLISS is an international network of research co-operation that aims to co-ordinate, develop and share expertise in innovative high performance policy research in co-operation with policy makers, National Olympic Committees, International sport organisations and researchers worldwide [33]. The first SPLISS project delivered in 2008 by an international consortium of researchers was a study comparing elite sport policies in six nations (Belgium, Canada, Italy, the Netherlands, Norway and the United Kingdom). SPLISS 1.0 involved 1,090 athletes, 273 coaches and 71 performance directors in the six nations, each of these individuals were asked to express and rate their views about the elite sport system in their nation [8]. The study remains one of the most inclusive studies at a meso-level and an outcome of the study was the development of a theoretical model of sport policy factors leading to international sporting success [33] SPLISS 2.0 study builds on the model and methodologies developed in SPLISS 1.0 and includes 15 nations and responses from more than 3,000 elite athletes, over 1,300 coaches and 241 performance directors [33].

The SPLISS model consists of nine pillars (or policy areas) that influence international sporting success, and specifies 31 sub-dimensions and 96 (originally 126) critical factors of success (CFSs) as key elements within pillars that are necessary to improve the elite sport success of a nation [8]. The SPLISS model uses stages of athletic development to thematically classify different key success determinants in elite sport policy [34]. At each stage of athletic development the SPLISS model distinguishes the inputs (Pillar 1, financial support) from throughputs (Pillars 2-9), indicating the processes in elite sport policies that may lead to a certain output (success) [6]. As the purpose of this paper is to review the applicability of models in relation to athlete development, it is appropriate to now focus on Pillar 4 (talent identification and development).

As discussed in section 2 of this paper the '10 year rule', which was first associated with chess [35] and later applied to sport [36], has become a central element of the LTAD model. Research in the past decade however has shown that this timeframe has increased as athletes are starting at a younger age with their sport [37], they train for more hours and more national and international competitions are organized for younger age categories [38]. In response to this increased performance pressure on athletes, many countries have set up programmes to support talent identification and talent development.

De Boscher et al., [33] explain that from a sport policy perspective, increased financial and performance pressures have guided sports teams and organisations to attempt to identify 'future stars' at increasingly earlier ages. However, the accuracy of early talent detection models would appear inversely related to the length of time over which the prediction is intended to span [33]. According to Vaeyens et al., [39] it is crucial that talent identification models have the ability to differentiate between an athlete's adolescent performance level and potential for progression. However, evaluation of talent identification models reveals that this distinction is rarely recognized and that talent is typically evaluated in terms of outstanding performance.

Following a successful talent identification process, athletes move to the next level of their development, the talent development phase. In the context of Pillar 4, young talents will generally make the transition from the local sport clubs to the formal competitive sport with a view to improve performance, as a first selection process and eventually be selected into a regional or national youth team [40]. During this phase of talent development significant time is spent on training with a shift from emphasizing fun (during the initiation) to more focus on skill development [41]. Talented junior athletes start to receive special attention and extra benefits from their sports club (or personal coach) and governing bodies. In this regard, talent development programmes must have long-term aims and methods implying to focus on those skills that: (a) are important at senior level; and (b) enhance a youngster's ability to learn, develop and progress successfully in the future [33]. However, programmes often over-emphasize immediate performance as opposed to learning. Consequently, these individuals may miss fundamental development experiences and early achievers may end up ill-prepared to successfully transfer from youth to senior level [39].

Wylleman et al., [34] explain that the progression of an athletic career cannot be seen as separate from athletes' 
development in other domains, such as the psychological, psychosocial and the academic/vocational level. In the context of the SPLISS model and specifically Pillar 4 these aspects of talent development are considered with regards to the national strategies aimed at the identification of young talent, how talent development is facilitated in different nations and what services are provided to support this. However, once a young person has chosen to participate in a sport on a regular basis, talent identification and development becomes a relevant part of a NGB planning process.

\section{Evaluating the Place of Equestrian Sport in the LTAD and SPLISS Model}

According to the $\mathrm{BEF}$, introduction to riding generally occurs around the age of 3 years, with riders then specialising in a specific discipline around the age of 16 . The age at which riders compete at the elite level can vary substantially, for example within the Olympic context, to date the youngest equestrian competitor was a 16 year old female and the eldest was a 72 year old male [42]. With regard to the LTAD, equestrianism does not therefore fall into either an early or late specialisation framework but is an 'early start, late specialisation' sport [43].

The fact that within equestrian sport, men and women can compete on an equal footing at all levels of competition and across a very wide age range is a prima facie example of equality rarely found in other sporting disciplines [44]. It is also an indication that chronological age may be less of a factor in equestrianism than in other sports [43]. Indeed, the BEF recommend that young participants (below the age of 16 for men and 15 for women) should be grouped according to maturation levels rather than chronological age [45]. However, in the Olympic disciplines, the British Equestrian teams are constructed via age classification: Youth Teams; Pony, riders aged 12-16 years; Junior, riders aged 14-18 years, Young Rider, riders aged 16-21 years and Senior Teams [46].

With regards to SPLISS Pillar 4, the structure of equestrian teams and competition at elite level mirrors the somewhat traditional model of development from junior to senior level. It is important to note however that although the structure of competition provides lower age range classifications, there is no 'masters' classification, which is often the case in other sports that encourage lifelong participation. Also due to the potential longevity of riders' careers at a senior level within the Olympic disciplines, transition from youth teams to senior teams is not always progressive despite proven performance at a junior level. The fact that age is not a limiting factor in performance means that many riders can compete in numerous Olympic cycles, thereby potentially limiting the opportunity for new riders to break into a senior team [46]. Therefore in equestrian sport it is not that development programmes over-emphasize immediate performance or that riders are ill-prepared to transfer from youth to senior level. Transference may be blocked due to a lack of opportunity to break into a senior team.

The majority of senior members of the British Equestrian Team will have had access to the performance pathways and will have ridden on Junior or Young Rider teams at the point of specialisation. However, there may be a long gap between active participation on a youth team and transition to a senior team. Therefore, it can be said that talent identification and development at the point of specialisation (micro-level) and performance/competition pathways (meso-level) has a degree of synergy. However, due to the potential longevity of equestrian sporting careers, and the required combination of an elite rider with an elite horse, it is difficult to map this at a senior level. The Showjumper, Tim Stockdale, first represented Great Britain on a Senior Team in 1988 aged 24, whilst he has represented his country on over 50 occasions he has only competed at one Olympic Games, Beijing 2008 [46]. In comparison, Stockdale's team mate at the Beijing Olympic Games, and indeed his team mate on numerous occasions, Nick Skelton, only 7 years older than Stockdale, has competed in every Olympic Games from the Atlanta Olympic Games 1996 to the Rio Olympic Games 2016.

The majority of elite riders begin their career at an early age working for other elite riders whereby they learn their craft alongside developing sporting experience [46]. Most professional riders do not derive sufficient income from competing and have to support their sporting careers by running their own equestrian businesses and secure an income via buying and selling, breeding and training horses across all levels of competition [46]. This type of business is not subjected to the seasonality effects associated with many other sport competition calendars, there is no off season. Certainly on the European circuit, riders will return from the Olympics to continue with domestic competition often taking out a string of horses to each competition, competing at various levels (including lower levels of competition) in order to bring on younger less experienced horses [46]. Involvement in equestrian sport can therefore be seen as a life-long lifestyle choice and when combined with early specialization and potential longevity of participation, there is the increased chance of one-dimensional sport specific preparation and a lack of development of core components of athleticism. At a micro-level, failure to address the core components of athleticism may result in the need for remedial work by riders later in their career.

At a meso-level, with the support of UK Sport lottery funding, the BEF has developed the World Class Programme which has been designed to support a pathway to success for Eventing, Showjumping, and Dressage [47]. The World Class Programme has been in existence since just before the Sydney Olympic Games. The Programme is not about 'support for all' but is about identifying the most talented athletes and working with them to ensure that they 
reach their maximum potential and deliver their best possible results at World level and Olympic Games [48].

Talent development programmes must have long-term aims and methods designed to focus skills that are important at senior level, and enhance a young athlete's ability to learn, develop and progress successfully in the future [33]. Equestrian sport faces a unique challenge in that there is a need to develop a World Class athlete (the rider) and a World Class horse. In order to cope with this multi-dimensional need, the BEF introduced an Equine Pathway (in partnership with the BEF Olympic Member Bodies) during $2006 / 2007$ to sit alongside the human development pathway [49]. The purpose of the Pathway is to identify horses that have the potential to develop into medal winning horses. The World Class Programme then works with and supports the riders and the owners of the horses in order to help them maximise the horses' potential. At Olympic level British riders must compete on British horses, therefore it is hoped that the Equine Pathway will encourage owners to keep their horses with British riders, which will further enhance Equestrian Team GBR chances in major competitions [49].

The World Class Programmes across all sports must focus their attention on three key areas. Firstly, identifying talent; secondly, developing talent and thirdly, producing performance on the World stage. The Equestrian World Class Programme is no different, although as previously outlined there is a need to do this not only with the rider but also with the horse. The World Class Programme fits into three conjoined areas: the Equine Pathway, the Development Programme and the Performance Programme and it is also split into areas of support such as coaching, equine health and research and development, including a support area for human health and fitness [47].

The BEF have adapted the LTAD model and refer to the athlete as participant, ultimately describing the model as the 'Equestrian-specific Long Term Participant Development (LTPD) framework' (Table 2) [45]. Specifically the BEF define participant as follows: 'a participant is an athlete who takes part in either riding, carriage driving or vaulting either as a competitor or for social or therapeutic reasons, whatever their ability' [45].

Table 2. Comparative LTAD and LTPD stages

\begin{tabular}{|c|c|c|c|}
\hline Stage & LTAD & LTPD & LTPD Age \\
\hline 1 & Active Start & Active Start & $\begin{array}{c}\text { Male 2-6 } \\
\text { Female 2-6 }\end{array}$ \\
\hline 2 & Fundamentals & Fundamentals & $\begin{array}{c}\text { Male 6-9 } \\
\text { Female 6-8 }\end{array}$ \\
\hline 3 & Learning to Train & $\begin{array}{c}\text { Learning to Take } \\
\text { Part }\end{array}$ & $\begin{array}{c}\text { Male 9-13 } \\
\text { Female 8-12 }\end{array}$ \\
\hline 4 & Training to Train & $\begin{array}{c}\text { Training to } \\
\text { Improve }\end{array}$ & $\begin{array}{c}\text { Male 13-15 } \\
\text { Female 12-14 }\end{array}$ \\
\hline 5 & $\begin{array}{c}\text { Training to } \\
\text { Compete }\end{array}$ & $\begin{array}{c}\text { Training to } \\
\text { Perform }\end{array}$ & $\begin{array}{c}\text { Male 16-23 } \\
\text { Female 15-21 }\end{array}$ \\
\hline 6 & Training to Win & $\begin{array}{c}\text { Training for } \\
\text { Excellence }\end{array}$ & $\begin{array}{c}\text { Male 23 }+ \\
\text { Female 21 + }\end{array}$ \\
\hline 7 & Active for Life & Active for Life & $\begin{array}{c}\text { Any age } \\
\text { participant }\end{array}$ \\
\hline
\end{tabular}

A review of the stages of the LTPD shows a clear correlation with those of the LTAD model especially in the early stages (1-3). Although an Active Start in equestrianism is not recommended from birth but from 2 years old. The transition from participation to development with regards to talent identification begins at Stage 5 of the LTPD, Training to Perform. At the micro-level it is at this stage that the BEF refer to 'individuals who have been identified as potential high achievers', this is within the age range of 15-21 for women and 16-23 for men [45]. However, it is interesting to note that at a macro-level performance pathways are in place for younger riders; Youth Teams, riders aged 12-16 years and Junior Teams, riders aged 14-18 years. This indicates that talent identification begins at stage 4: Training to Improve. It is also important to note that at a macro-level these 'Teams' are discipline specific, for example there will be a Junior Showjumping Team. Talent identification and associated selection onto a specific team would indicate a discipline specialisation at this point, which could be as young as 12 years old [50]. However, at the micro-level the BEF emphasise a multidisciplinary approach until at least stage 5 of the LTPD (Males 16-23 years, Females 15-21 years). Therefore there appears to be a degree of misalignment between micro-level development model and the meso-level framework with regards to competition structure and development pathways.

\section{Conclusions and Recommendations}

This preliminary investigation highlights some of the sport specific nuances of equestrianism and how these apply to talent identification and development models at the microand macro-level. In the case of equestrian sport, this review highlights the difficulty in profiling equestrian athletes using age as a variable and the added performance consideration of the need for an elite equine athlete as primary factors for consideration. Results from this study indicate that talent identification and development of the rider at the point of specialisation (micro-level) and performance/competition pathways (meso-level) at youth level have a degree of synergy but it is difficult to map this at a senior level of competition. Whilst the BEF have created their own specific LTPD model, which to some extent reflects the early start late specialisation development framework of equestrian sport, there appears to be a degree of misalignment between micro-level development recommendations and macro-level performance pathways. The ' 10 year rule', has become a central element of both the LTAD and SPLISS model. Yet it remains unclear how this translates to an early start-late specialisation sport such as equestrianism. Both micro- and macro-level models emphasise the progression from fun to skill development but it seems difficult to pinpoint this transition within equestrian sport due to conflicting guidelines with regards specialisation. As De Boscher et al., 
[33] point out, sport organisations are under increased pressure to attempt to identify and support 'future stars', increasingly at a younger age. However, the accuracy of early talent detection models would appear inversely related to the length of time over which the prediction is intended to span [33]. Despite the BEF recommendations that a multidisciplinary approach be taken until at least 15 years old for female riders and 16 years old for male riders, talent identification and discipline specific performance pathways are in place for riders as young as 12 years old.

Within the context of equestrian sport, and considering the lifestyle approach too many riders' careers, there is a risk that the combination of an early specialization and potential longevity of participation, may increase the chance of one-dimensional sport specific preparation and a lack of development of core components of athleticism. At a micro-level, failure to address the core components of athleticism may result in the need for remedial work by riders later in their career. It therefore raises the question of whether the elongated careers of equestrian athletes supersede the need to find talent at such an early age. Indeed the consequences of such a specialization model may include overuse injury, burnout and dropout. Due to the potential longevity of a rider's career at the elite level, there also appears to be a barrier which prevents new talent breaking into the senior teams.

Based on this preliminary investigation I conclude that existing micro- and meso-level models can be applied to some extent, to equestrian sport if adapted to take into consideration the sport specific nuances. However, with regards to talent identification and development frameworks, I recommend a paradigm shift is required for this sport, to move from the traditional chronological age classification of competition. I recommend that further research is required relating to athlete profiling in order to truly test / define the classification of early start-late specialisation. Results from this preliminary investigation highlight that a riders career can last 60 years, with specialization pathways in place from 12 years and no 'masters' age classification. I suggest the term 'late' specialization needs to be reviewed in the context of potential career longevity. Meso-level changes to competition structure, to age categorized competition and discipline specific specialization may help to address micro-level sport specific issues such as avoidance of burnout and the development of well-rounded athletes. As discussed throughout this paper, equestrian sport is unique for several reasons, including the age range of competitors, none sex-segregated competition and the combination of a human and equine athlete. I conclude that rather than adapt existing models to accommodate these unique characteristics, a paradigm shift is required which may result in the development of sport-specific frameworks for talent identification and development.

\section{REFERENCES}

[1] Bergsgard, N, A., Houlihan, B., Mansget, P., Nodland, S. I., \& Rommetveldt, H. (2007). Sport Policy: A comparative analysis of stability and change. London: Elsevier.

[2] De Bosscher, V., De Knop, P., \& van Bottenburg, M. (2009). An analysis of homogeneity and heterogeneity of elite sports systems in six nations. International Journal of Sports Marketing and Sponsorship, 10(2), 111-131.

[3] Digel, H., Burk, V., \& Fahrner, M. (2006). High performance sport. An international comparison (Vol. 9). Weilheim/Teck, Tubingen: Brauer.

[4] Green, M. \& Houlihan, B. (2005). Elite sport development. Policy learning and political priorities. London and New York: Routledge.

[5] Truyens, J., De Bosscher, V., Heyndels, B., \& Westerbeek, H. (2014). A resource-based perspective on countries' competitive advantage in elite athletics. International journal of Sport Policy and Politics. 6(3), 459-489.

[6] De Bosscher, V., De Knop, P., \& van Bottenburg, M. (2007). Sport policy factors leading to international sporting success (Published doctoral thesis, Brussels, BE: VUBPRESS).

[7] Houlihan, B. \& Green, M. (2008). Comparative elite sport development. In /b. Houlihan \& M. Green (eds), Comparative elite sport development: Systems, structures and public policy (1-25). London: Butterworth- Heineman.

[8] De Bosscher, V., De Knop, P., van Bottenburg, M., \& Shibli, S. (2006). A Conceptual framework for analysing sports policy factors leading to international sporting success. European Sport Management Quarterly, 6(2), 185-215.

[9] Ford, P., De Ste Croix, M., Lloyd, R., Meyers, R., Moosavi, M., Oliver, J., Till, K., \& Williams, C. (2011). The Long-Term Athlete Development model: Physiological evidence and application. Journal of Sports Sciences, 29(4), 389-402.

[10] De Bosscher, V., Sotiriadou, P., \& Brouwers, J., \& Truyens, J. (2015). Systems and athletes. Integrating the micro- and meso-level approaches to athlete development and success. In S S Andersen, L. T. Ronglan \& B. Houlihan (Eds), Managing Elite Sport Systems: Research and Practice (143-161). London and New York: Routledge.

[11] Sotiriadou, P., Gowthorp, L., \& De Bosscher, V. (2014). Elite sport culture and policy interrelationships: the case of Sprint Canoe in Australia. Leisure Studies, 33(6), 598-617.

[12] de Haan, D., \& Dumbell, L.C. (2016). Equestrian Sport at the Olympic Games from 1900 - 1948. The International Journal of the History of Sport, 33(6-7), 648-665.

[13] Lang, M., \& Light, R., (2010). Interpreting and implementing the Long Term Athlete Development Model: English swimming coaches' views on the (Swimming LTAD) in practice. International Journal of Sports Science and Coaching, 5(3), 389-402.

[14] Baquet, G., Van Praagh, E., \& Berthoin, S. (2003). Endurance training and aerobic fitness in young people. Sports Medicine, $15,1127-1143$

[15] Boisseau, N., \& Delamrche, P. (2000). Metabolic and 
hormonal responses to exercise in children and adolescents. Sports Medicine, 30, 405-422.

[16] Naughton, G., Farpour-Lambert, N., Carlson, J., Bradney, M., $\&$ Van Pragh, E. (2000). Physiological issues surrounding the performance of adolescent athletes. Sports Medicine, 30, 309-325.

[17] Viru, A., Loko, J., Harro, M., Volver, A., Laaneots, L., \& Viru, M. (1999). Critical periods in the development of performance capacity during childhood and adolescence. European Journal of Physical Education, 4, 75-119.

[18] Balyi, I., \& Hamilton, A. (2004). Long-Term Athlete Development: Trainability in children and adolescents. Windows of opportunity. Optimal trainability. Victoria, BC: National Coaching Institute British Columbia \& Advanced Training and Performance Ltd.

[19] Harre, D. (1982). Principles of sports training. Berlin: Sportsverlag.

[20] Balyi, I., \& Way, R. (1995). Long-term planning for athlete development: The training to train phase. $B C$ Coach (Canada), Fall, 2-10.

[21] Bompa, T. (1995). From childhood to champion athlete. West Sedona, AZ: Veritas Publishing.

[22] Ericsson, K.A., Krampe, R.T., \& Tesch-Romer, C. (1993). The role of deliberate practice in the acquisition of expert performance. Psychological Review, 100(3), 363-406.

[23] Black, D.E., \& Holt, N.L. (2009). Athlete development in ski racing: Perceptions of coaches and parents. International Journal of Sports Science and Coaching, 4(2), 245-260.

[24] Lang, M. (2009). Swimming in the Panopticon: An ethnographic study of good practice in competition youth swimming. ( $\mathrm{PhD}$ Thesis, Leeds Metropolitan University, UK).

[25] Abbott, A., Collins, D., Martindale, R. \& Sowerby, K. (2002). Talent identification and development: An academic Review. Sport Scotland. Edinburgh.

[26] Martindale, R. J. J., Collins, D. \& Abraham, A. (2007) Effective talent development: The elite coach perspective in UK sport. Journal of Applied Sport Psychology, 19, 187-206.

[27] Salguero, A., Gonzalez-Boto, R., Tuero, C. \& Marquez, S. (2003). Identification and drop out reasons in young competitive swimmers. Journal of Sports Medicine and Physical Fitness, 43(4), 530-534.

[28] Valeriote, T.A. \& Hansen, L. (1986). Youth sport in Canada. In M.R. Weiss \& D. Gould, (Eds) Sport for children and youths. (1-15). Champaign, IL: Human Kinetics.

[29] Gould, D., Gianinni, J., Krane, V. \& Hodge, K. (1990). The educational needs of elite U.S. National Pan American and Olympic Coaches. Journal of Teaching in Physical Education, 9, 332-344.

[30] Gilbert, W., \& Trudel, P. (2001). Learning to coach through experience: Reflection in model youth sport coaches. Journal of Teaching and Physical Education, 21, 16-34.

[31] Cushions, C.J., Armour, K.M., \& Jones, R.L. (2003). Coach education and continuing professional development: Experience and learning to coach. Quest, 55, 215-230.
[32] Norris, S.R., \& Smith, D.J. (2002). Planning, periodization, and sequencing of training and competition: the rationale for a competently planned, optimally executed training and competition program, supported by a multidisciplinary team. In M, Kellmann (Ed.), Enhancing recovery: Preventing underperformance in athletes. (119-141). Champaign, IL: Human Kinetics.

[33] de Bosscher, V., Shibli, S., Westerbeek, H., \& van Bottenburg, M. (2015). Successful Elite Sport Policies: An International Comparison of the Sports Policy Factors Leading to International Sporting Success (SPLISS 2.0) in 15 Nations. Maidenhead: Meyer \& Meyer Sports Ltd.

[34] Wylleman,P., Alfermann, D., \& Lavalle, D. (2004). Career transitions in sport: European perspectives. Psychology of Sport and Exercise, 5(1), 7-20.

[35] Chase, W. G. \& Simon, H. A. (1973). Perception in chess. Cognitive Psychology, 4, 55-81.

[36] Ericsson, K.A. (2003). Development of elite performance and deliberate practice: An update from the perspective of the expert performance approach. In K. Starkes \& K.A. Ericsson (Eds.), Expert performance in sports: Advances in research on sport expertise (49-85). Champaign, IL: Human Kinetics.

[37] van Bottenburg, M. (2009). Op jacht naar goud. Het topsportklimaat in Nederland, 1998-2008. [The hunt for gold. The elite sport climate in The Netherlands, 1998-2008]. Niewegein: Arko Sports Media.

[38] Gullich, A., E. Emrich, S. Espwall, M. Olyslager, R. Parker, and V. Rus (2004). Education in Elite Sport in Europe. [Online]. Available: http://www.jugendprojekte-im-sport.de/photos/projekte/medi en/ EESEtechnicalreport.pdf

[39] Vaeyens, R., Williams, A.M., \& Philippaens, R. (2008). Talent Identification and Development Programmes in Sport. Sports Medicine, 38(9), 703-14.

[40] De Knop, P., Wylleman, P., Theeboom, M., De Martelaer, K., Van Hoecke, J., \& Van Heddegem, L. (1999). The role of contextual factors in youth's participation in organised sport. European Physical Education Review, 5(1), 91-106.

[41] Bloom, B.S. (1985). Developing talent in young people. New York: Balantine.

[42] de Haan, D., Henry, I., \& Sotiriadou, P. (2015). Evaluating the place of equestrian sport in the Long-Term Athlete Development (LTAD) and the Sport Policy factors that Lead to International Sporting Success (SPLISS) models. SPLISS conference, Melbourne, Australia.

[43] Dumbell, L., Johnson, J-L., \& de Haan, D. (2010) Demographic profiling of elite dressage riders. The International Journal of Sport and Society, 1(3), 15-24.

[44] de Haan, D., Sotiriadou, P., \& Henry, I. (2015). The lived experience of sex integrated sport and the construction of athlete identity within the Olympic and Paralympic Equestrian disciplines. Sport in Society, 18, 1-18.

[45] British Equestrian Federation (n.d.) Long term participant development for equestrian riders, drivers and vaulters. [Online]. Available: http://www.bef.co.uk/repository/downloads/riders/riderdevelo pment/ltpd2013v5.pdf 
[46] de Haan, D. (2015). Evaluating the Experience of the Olympic and Paralympic Games in the Career Histories of Elite Equestrian Athletes. (Published doctoral thesis, Loughborough University, UK).

[47] British Equestrian Federation Performance [Online]. Available:

(2014). World Class http://www.bef.co.uk/Performance-Programme
[48] UK Sport (2014). World Class Performance Programme [Online]. Available:

http://www.uksport.gov.uk/pages/wc-performance-programm e

[49] British Equestrian Federation (2014). Rider Development: Intro Para-Equestrian Competitions [Online]. Available: http://www.bef.co.uk/Para-Intro-Shows

[50] The Pony Club (nd). Pony Club Talent Pathway. [Online]. Available:

http://www.pcuk.org/index.php/training/riderdevelopmentpat hway 